\title{
Dois Irmãos: \\ No registro de memórias, a constituição da identidade
}

\author{
Juracy Assmann Saraiva * \\ Carlos Böes de Oliveira ** \\ Marinês Andrea Kunz ***
}

\section{Resumo}

Este artigo analisa a construção da identidade do narrador em Dois Irmãos, romance do escritor amazonense Milton Hatoum. Ele salienta a importância da recuperação da oralidade e da observação como estratégias que possibilitam instituir a narrativa e conferir uma identidade ao narrador, que se constitui, simultaneamente, em observador e protagonista dos eventos relatados. 0 s referenciais teóricos utilizados sustentam a importância da narrativa e do papel do narrador e do leitor em sua construção, citando-se críticos como Paul Ricoeur, Walter Benjamin, Silviano Santiago, Juracy Assmann Saraiva, Umberto Eco e Wolfgang Iser. A análise permite concluir que as perguntas que fundam a narração sugerem diferentes interpretações, não apenas para o narrador, mas também para o leitor, que se situa diante de um romance aberto, cujos sentidos provocam uma nova e continuada leitura.

\section{Palavras-chave}

Narrador. Leitor. Dois Irmãos.

\section{Abstract}

This paper analyzes the construction of identity in the narrator of Dois Irmãos, novel from the amazon writer Milton Hatoum. It emphasizes the importance of oral tradition recuperation

\footnotetext{
* Juracy Assmann Sarayva é Pós-Doutora em Teoria da Literatura pela Unicamp, Professora e Pesquisadora da Universidade Feevale e do Conselho Nacional de Desenvolvimento Científico e Tecnológico (CNPq). E-mail: Juracy@feevale.br .

** Caio Böes de Oliveira é Bolsista do Programa de Suporte à Pós-graduação de Instituições de Ensino Particulares (PROSUP) da Coordenação de Aperfeiçoamento de Pessoal de Nível Superior (CAPES) no Doutorado de Processos e Manifestações Culturais da Universidade Feevale e da University of New Mexico. E-mail: caio.boes@gmail.com .

*** Marinês Andrea Kunz é Doutora em Letras pela Pontifícia Universidade Católica do Rio Grande do Sul (PUC-RS), Professora e Pesquisadora da Universidade Feevale. E-mail: marinesak@feevale.br .
} 
and observation as strategies that enable the narrative to be established as much as to bestow an identity to the narrator that is constituted, simultaneously, as an observer and protagonist of the events described. The theoretical references are used to sustain the relevance of the narrative and of the role of the narrator and the reader in its construction, quoting critics such as Paul Ricoeur, Walter Benjamin, Silviano Santiago, Juracy Assmann Saraiva, Umberto Eco and Wolfgang Iser. This analysis allows the conclusion that the questions that found the narration suggest different interpretations not only to the narrator, but also to the reader that is placed before an open novel, whose meanings provoke a new and continuous reading.

\section{Keywords}

Narrator. Reader. Dois Irmãos.

\section{Introdução}

"Eu não sabia nada de mim, como vim ao mundo, de onde tinha vindo. A origem: as origens".

Milton Hatoum

A epígrafe elucida o conflito de Nael, narrador e personagem de Dois Irmãos (2006), romance de Milton Hatoum ${ }^{1}$. À margem da vida, à margem do espaço familiar, incompleto, vivendo com as sobras dos outros, com as sobras da memória dos outros, com os silêncios e esquecimentos que habitam a memória desses outros, com restos como roupas, livros, cadernos, o narrador do romance tenta reconstituir sua história e sua identidade ao contar a trajetória dos que o cercam. E, nessa tentativa de busca da identidade, o leitor do romance absorve a sequência temporal das ações e o deslocamento espacial que assinalam o declínio e a transformação de uma família de origem libanesa, da sociedade amazonense e do país, enquanto, paralelamente, Nael se constitui como sujeito por meio do ato de narrar.

Paul Ricoeur registra a relevância do ato de narrar e sua correspondência com a experiência da temporalidade para o ser humano, que ganha forma

\footnotetext{
${ }^{1}$ Milton Hatoum é descendente de libaneses e conflitos de identidade relacionados aos grupos étnicos e questões de ordem pessoal são tema de suas obras. É autor de quatro romances premiados, Relato de um Certo Oriente (1989), Dois Irmãos (2000), Cinzas do Norte (2005) e Órfãos do Eldorado (2008), entre outros contos e crônicas. Sua obra foi traduzida em dez línguas e publicada em quatorze países.
} 
por meio de narrativas:

[...] existe, entre a atividade de narrar uma história e o caráter temporal da experiência humana, uma correlação que não é puramente acidental, mas apresenta uma forma de necessidade transcultural. $\mathrm{Ou}$, para dizê-lo de outra maneira: o tempo torna-se tempo humano na medida em que está articulado de modo narrativo, e a narrativa alcança sua significação plenária quando se torna uma condição da existência temporal.

(2010, p.93 - grifo do autor).

Ao assinalar a relação fundamental entre a temporalidade e o narrar, Ricoeur refere, também, a importância das narrativas para os indivíduos, pois elas ajudam-nos a responder às suas inquietações diante da realidade, por apresentarem, de forma concreta e inteligível, situações humanas que a experiência cotidiana expõe de modo precário e confuso. Consequentemente,

“[...] imitar ou representar a ação, é, primeiro, pré-compreender o que ocorre com o agir humano, com sua semântica, com sua simbólica, com sua temporalidade. É sobre essa pré-compreensão, comum ao poeta e a seu leitor, que se ergue a tessitura da intriga e, com ela, a mimética textual e literária". (2010, p. 101).

Com efeito, o desejo de compreender o lugar que a ele cabe no núcleo da família, constituída por Omar e Zana, move Nael a articular eventos a partir de um plano temporal marcado pela perturbação de sua própria memória, que se alimenta do olhar sobre o entorno e do relato de outras personagens. A relevância do ato narrativo e o desenho das circunstâncias da vida de Nael conduzem a análise a refletir sobre a concepção do narrador, cuja problemática "encaminha-se paralelamente às discussões teóricas que definem a especificidade da narrativa enquanto fenômeno estético, determinando o instrumental próprio à sua análise crítica" (SARAIVA, 2009, p.25).

A abordagem metodológica deste artigo ancora-se, pois, em teorias narratológicas que explicitama importância do narrador e, sistematicamente, investem na do próprio leitor, visualizado como agente da produção textual. Sob o primeiro aspecto, destacam-se as contribuições de Walter Benjamin e de Silviano Santiago: para aquele, a "memória é a mais épica de todas as faculdades" (1985, p. 210) e a experiência é condição que confere 
autoridade a quem narra, estabelecendo-se a proximidade entre o narrador e seu ouvinte por meio da autenticidade da narração; Silviano explicita os paradigmas que concernem ao fazer discursivo do narrador pós-moderno e a suas múltiplas facetas técnicas e atesta que esse narrador dá luz a experiências alheias, captadas pelo olhar, e não as que são expostas como tendo sido vividas, definindo-se uma relação de distanciamento entre o fato narrado e seus receptores.

Em Dois Irmãos, a composição da subjetividade narradora permite a convergência desses dois referenciais, e, em vista da complexidade de seu processo de narração, pressupõe a ativa participação do leitor. Se "um texto postula o próprio destinatário como condição indispensável não só da própria capacidade concreta de comunicação, mas também da própria potencialidade significativa" (ECO, 1979, p. 37), o leitor é desafiado a considerar a transposição de múltiplos pontos de vista, a preencher lacunas dos eventos relatados e, simultaneamente, a manter uma atitude de distanciamento diante deles.

\section{0 narrador híbrido de Dois Irmãos}

O processo de narração de Dois Irmãos revela-se fulcro do entendimento da estrutura do romance, mas sua análise está condicionada à apreensão da diegese, que se situa na cidade de Manaus, no período que se estende de 1920 ate 1970. Nesse lapso de tempo, ocorre a composição e a dissolução da família de Halim e de Zana. Essa é filha de Galib, de origem libanesa, proprietário de um restaurante chamado Biblos, especializado em comida libanesa com toques manauaras. O rapaz frequenta o restaurante e apaixonase por Zana. Para aproximar-se de sua amada, Halim pede a seu amigo e poeta, Tannus, que componha um abbas, que ele declama para seduzir a jovem. O poema amoroso torna-se uma espécie de canto de acasalamento do casal, e a ele Halim recorre sempre que deseja encantar a esposa. Após casarem, o casal adota uma índia, procedimento que se caracteriza como uma transação financeira, e Domingas, a índia, é antes uma escrava do que uma empregada. Halim não queria filhos, mas a esposa insiste e geram três crianças. Primeiro vêm os gêmeos que dão título à narrativa, Yaqub e Omar, e logo depois nasce Rânia. Os gêmeos, embora idênticos fisicamente, possuem personalidades distintas: Yaqub é reservado e quieto, enquanto Omar, o caçula, é extrovertido, destemido e apresenta um comportamento errático e violento. Zana faz de Omar seu favorito, mimando-o e dedicando-se de 
tal forma aos seus cuidados que o próprio marido se sente negligenciado, enquanto Domingas cuida de Yaqub. Na adolescência, uma briga entre os gêmeos gera um ódio mútuo que fará com que nunca mais se reconciliem. No período da adolescência dos gêmeos, nasce Nael, filho de Domingas, cuja paternidade jamais é esclarecida, instalando-se a suspeita de ter ele sido gerado por um dos irmãos. Os desacertos entre eles amarguram a vida de Halim e de Zana, consumindo-se não apenas a alegria do casal, mas também a fortuna que o comerciante acumulara. Paralelamente, a cidade de Manaus altera-se, e a vida urbana, alicerçada em um falso progresso, elimina a interação entre os membros da comunidade libanesa.

Estabelece-se, portanto, uma relação análoga entre a ruína familiar e sua completa desestruturação com a transformação da cidade de Manaus, a qual pode ser vista, pelos leitores, como um reflexo de forças híbridas que invadem os territórios familiar e geográfico. Assim, Nael, filho bastardo da família libanesa - que se orgulhava em manter as características culturais de seu país de origem - e de uma índia amazonense, passa a ser responsável por manter a "linhagem" da família, já que Yaqub mora em São Paulo e não se interessa mais em regressar; os outros descendentes, Rânia e Omar, não casam nem têm filhos declarados. Consequentemente, o representante da família é Nael, e sua figura cria um paralelismo com a própria cidade de Manaus: uma cidade em mudanças, onde a opacidade de histórias e origens impera e onde se enovelam discursos e fazeres estranhos. Nael é "filho" dessa Manaus, sendo um ser híbrido e multicultural, assim como a cidade em que habita.

Nos capítulos iniciais de Dois Irmãos, o leitor defronta-se com a dificuldade de identificar o tema central da trama bem como a instância narrativa, interrogando-se sobre o protagonismo das personagens e, até mesmo, sobre a proveniência do ângulo da narração. No capítulo quatro, o leitor tem acesso ao conflito nuclear - a busca da origem ou das origens de Nael - e à delimitação da subjetividade narradora:

"Eu não sabia nada de mim, como vim ao mundo, de onde tinha vindo. A origem: as origens. Meu passado, de alguma forma palpitando na vida dos meus antepassados, nada disso eu sabia. Minha infância, sem nenhum sinal de origem. É como esquecer uma criança dentro de um barco num rio deserto, até que uma das margens a acolhe. Anos depois, desconfiei: um dos gêmeos era meu pai".

(HATOUM, 2006, p.54) 
Em uma narração marcada pela ruptura da sequencialidade das ações, Nael expõe-se como um narrador que se concentra nos episódios que manifestam a inimizade visceral entre os filhos de Halim e de Zana, embora, deixe, também, suas impressões de filho bastardo, que desconhece a identidade do pai. A opacidade da origem de Nael é reforçada pelo silêncio em torno de seu nome, enunciado apenas uma vez na narrativa, e essa é uma das estratégias que invocam a participação do leitor, que se situa diante de uma situação narrativa ambígua em que o narrador assume o papel de testemunha, embora o conflito nuclear da diegese seja o de sua identidade. A necessidade de o leitor colaborar com a construção do texto presentifica a afirmação de Umberto Eco: “Portanto, prever o próprio leitor-modelo não significa 'esperar' que ele exista, mas significa também mover o texto de modo a construí-lo. O texto não apenas repousa numa competência, mas contribui para produzi-la" (ECO, 2012, p.40).

Nael, como narrador, utiliza-se dos relatos de outras personagens, principalmente de Halim e Domingas, para traçar sua origem e tentar descobrir quem é seu pai. Assim, é a partir de relatos cheios de imprecisões e silêncios, suscitados pela memória dos outros e por informações que eles estão dispostos a dividir, que Nael constrói, através da escrita, um mosaico em que se cruzam discursos vários, que revelam a estrutura familiar da casa libanesa, onde Nael e Domingas vivem à margem, como testemunhas mantidas à distância. Porém, a perspectiva do narrador não se restringe ao reduto familiar, pois, atuando como menino de recados, ele recolhe indícios dos processos de transformação da cidade de Manaus, de uma comunidade de imigrantes e de seu processo civilizatório, da decadência de uma antiga classe dominante, da condição social dos índios, da diversidade e da devastação do ambiente natural. O aviltamento dos indígenas reporta a Domingas, cuja comunidade é desmantelada, sendo ela alfabetizada, instrumentalizada para trabalhar como doméstica e colocada à "venda".

A deterioração do espaço urbano fica visível na passagem em que Omar descreve as vicissitudes pelas quais a cidade de Manaus passa:

“O Café Mocambo fechara, a praça das Acácias estava virando um bazar. Sozinho à mesa, ele ia contando suas andanças pela cidade. A novidade mais triste de todas: o Verônica, lupanar lilás, também fora fechado. "Manaus está cheia de estrangeiros, mama. Indianos, coreanos, chineses... O centro virou um formigueiro de gente do interior... Tudo está mudado em Manaus".

(HATOUM, 2006, p.167 - grifo nosso) 
As mudanças de Manaus encontram paralelo na estrutura familiar que, como um microcosmo, reflete o macrocosmo, que é a cidade. A família libanesa, da qual Nael é filho bastardo, representa uma classe que havia adquirido certo prestígio, mas que, em consonância com a própria cidade, se transfigura e perde sua coesão, pelo esfacelamento dos laços étnicos e afetivos. Na passagem subsequente, os fundadores da família libanesa, Zana e Halim, já estão mortos, e o leitor presencia, a partir do olhar de Nael, o desmonte da estrutura física da casa, onde uma cultura identitária um dia se fizera presente:

"Ela morreu quando o filho caçula estava foragido. Não chegou a ver a reforma da casa, a morte a livrou desse e outros assombros. Os azulejos portugueses com a imagem da santa padroeira foram arrancados. E o desenho sóbrio da fachada, harmonia de retas e curvas, foi tapado por um ecletismo delirante. A fachada, que era razoável, tornou-se uma máscara de horror, e a ideia que se faz de uma casa desfez-se em pouco tempo".

(HATOUM, 2006, p.190)

Portanto, Nael narra a partir do ponto de vista de um sujeito que não vivenciou a maioria dos acontecimentos, espelhando-se, nesse processo de comunicação narrativa, sua posição social: ele é um narrador à margem dos acontecimentos. É por meio da audição e da observação que ele constrói seu conhecimento para dar-lhe forma na escrita, com o intuito de desvelar a secreta história de sua origem.

Silviano Santiago, refletindo acerca do narrador pós-moderno, interroga:

“Quem narra uma história é quem a experimenta, ou quem a vê? Ou seja: é aquele que narra ações a partir da experiência que tem delas, ou é aquele que narra ações a partir de um conhecimento que passou a ter delas por tê-las observado em outro?" (SANTIAGO, 2002, p.40).

O narrador de Dois Irmãos se enquadra em ambas as tipologias, já que as ações permeiam um período de tempo que precede seu nascimento em algumas décadas, alcançam o período de sua vida adulta e se estendem para o momento da narração, quando várias personagens já estão mortas. Assim, Nael ora é o sujeito da enunciação de eventos que lhe foram narrados, ora é, simultaneamente, agente das ações e sujeito da enunciação.

Em suas interrogações, Silviano Santiago coloca em cheque a questão da 
autenticidade do relato. Para o teórico, a autenticidade ou a fidedignidade é, por um lado, indiscutível quando o narrador é parte central das ações narradas e detém pleno domínio dos acontecimentos; por outro lado, ela deve ser questionada quando os acontecimentos narrados provêm da observação do narrador quanto ao que aconteceu a outras personagens (2002, p.40). Instala-se, nesse caso, a dúvida sobre a adequada percepção do narrador a respeito dos eventos, entretanto a falta de credibilidade do sujeito da enunciação não compromete a verossimilhança da narrativa, no âmbito da qual a estratégia da composição de um narrador dúbio pode atender à intencionalidade do texto ${ }^{2}$. Paralelamente, por ter um papel secundário na evolução das ações e valer-se do narrar dos outros para compor os eventos que desconhece, Nael lida constantemente com imprecisões e lacunas, jamais alcançando seu objetivo, isto é, o conhecimento a respeito da identidade de seu pai. Esse mesmo problema é transferido ao leitor, cujas perguntas a respeito do dilema de Nael não encontram respostas conclusivas.

Logo no início da narrativa, quando o leitor ainda não sabe quem é o agente da narração e qual a posição dele no universo das personagens, há um comentário do narrador sobre sua condição de observador marginalizado:

\begin{abstract}
“Isso Domingas me contou. Mas muita coisa do que aconteceu eu mesmo vi, porque enxerguei de fora aquele pequeno mundo. $\mathrm{Sim}$, de fora e às vezes distante. Mas fui o observador desse jogo e presenciei muitas cartadas, até o lance final".
\end{abstract}

(HATOUM, 2006, p.23).

A posição marginal do narrador-personagem amplia o escopo das incertezas, apresentando-se a narrativa como inconsistente no que tange à aceitação da veracidade do narrado, ainda que seja absolutamente verossímil.

Em Dois Irmãos, “[...] não encontramos um indivíduo confiante em sua capacidade de conhecer o passado com o mínimo de certeza. Isso não é uma transcendência em relação à história, mas sim uma inserção problematizada da subjetividade na história" (HUTCHEON, 1991, p. 156). A narrativa

\footnotetext{
${ }^{2}$ Dom Casmurro, romance de Machado de Assis, exemplifica uma estratégia narrativa embasada na ambiguidade do narrador, a qual exige o distanciamento crítico do leitor quanto à exposição dos acontecimentos.
} 
sustenta-se, assim, sobre a memória e a imaginação, e esses elementos não se refletem apenas no processo de narração, mas incidem sobre o próprio leitor que reconstrói um relato incompleto. “A ficção pós-moderna sugere um reescrever ou reapresentar um passado na ficção e na história, é em ambos os casos - revelá-lo ao presente, impedi-lo de ser conclusivo e teleológico" (Idem, 1991, p.147).

Há trechos em que o narrador explica o método narrativo, salientando sua imprecisão de observador, situado em uma posição exterior e marginal à ação, mas em que o prazer de narrar e de ser ouvido atuam como motivadores da instalação do fantasioso. Logo, estimulado pelas afirmações de Nael, o leitor levanta dúvidas acerca da veracidade e da precisão das observações do próprio Nael:

“O que me dava um pouco de folga e certo prazer era uma tarefa que não chegava a ser um trabalho de verdade. Quando as casas da rua explodiam em gritos, Zana me mandava zarelhar pela vizinhança, eu cascavilhava tudo, roía os ossos apodrecidos dos vizinhos. Era cobra nisso. Memorizava as cenas, depois contava tudo para Zana, que se deliciava, os olhos saltando de tanta curiosidade: "Conta logo, menino, mas devagar... sem pressa". Eu me esmerava nos detalhes, inventava, fazia uma pausa, absorto, como se me esforçasse para lembrar, até dar o estalo".

(HATOUM, 2006, p.64 - grifo nosso).

As estratégias utilizadas para espionar a vida dos vizinhos e a própria narração aguçam o prazer dos sentidos e estão presentes no modo como o receptor é envolvido na narrativa. O uso de silêncios, a investigação por meio do ouvir e do ver, a instalação de pressuposições são elementos marcantes no arco discursivo da narrativa de Dois Irmãos, cujas estratégias provocam sensações no leitor, induzindo-o a situar-se diante de uma encenação dramática.

Essa idiossincrasia transcende o paradigma do narrador pós-moderno, visto que as estratégias narrativas do romance de Milton Hatoum exemplificam constatações que Walter Benjamim faz sobre o narrador. Para este, a humanidade perdeu o contato com a arte de narrar, pois ela se relaciona com a troca de experiências pessoais, e essa se tornou tão pobre que já não há o que narrar.

"Por mais familiar que seja seu nome, o narrador não está de fato presente entre nós, em sua atualidade viva. Ele é algo de distante, 
e que se distancia ainda mais" (BENJAMIN, 1994, p.197), devido ao declínio da troca de experiências entre os homens. Hoje, as pessoas não conseguem mais narrar a sua própria vivência, por isso "a arte de narrar está em vias de extinção. São cada vez mais raras as pessoas que sabem narrar devidamente".

(BENJAMIN, 1994, p.197).

Benjamin identifica dois tipos de narrador: o das tradições orais, aquele que transmite ao seu ouvinte um intercâmbio de experiências e conhecimentos e cuja narrativa tem um caráter prático e utilitário; e o narrador do romance, um indivíduo isolado, "que não pode mais falar exemplarmente sobre suas preocupações mais importantes e que não recebe conselhos nem sabe dá-los" (BENJAMIN, 1994, p.201). Segundo ele, o romance anuncia a morte da narrativa, visto que "ele nem procede da tradição oral nem a alimenta" (BENJAMIN, 1994, p.201), distinguindo-se, portanto, da essência da narrativa. $\mathrm{O}$ teórico registra, ainda, a presença de nova forma de comunicação, a informação, que deve ser plausível e, por isso, se opõe ao miraculoso, além de menosprezar o saber que vem de longe, dando evidência ao acontecimento próximo. Benjamin afirma que esse tipo de comunicação é "incompatível com o espírito da narrativa", visto que se efetiva por meio de explicações, no que é secundado por Silviano Santiago: “[...] uma narrativa não deve estar interessada em transmitir o 'puro de si' da coisa narrada como uma informação ou um relatório. A narrativa é narrativa porque ela mergulha a coisa na vida do narrador para depois retirá-la dele" (SANTIAGO, 2002, p.46).

Confrontando a técnica narrativa da tradição oral, privilegiada por Benjamin, com a de Dois Irmãos, verifica-se que esta dialoga com aquela, ainda que apresente elementos peculiares ao processo de narração da pósmodernidade. A recuperação de relatos orais é necessária, para que Nael conheça o passado e suas origens, mas elas não são coincidentes, colocando em dúvida a informação. Apesar disso, as narrativas transmitidas a Nael por Halim, Zana, Domingas e outras personagens são fundamentais para que ele possa apreender sua história e a dos que o cercam. Nesta passagem, Halim descreve a Nael como Domingas, a mãe do narrador, veio parar na família:

"Uma menina mirrada, que chegou com a cabeça cheia de piolhos e rezas cristãs", lembrou Halim. "Andava descalça e tomava benção da gente. Parecia uma menina de boas maneiras e bom humor: nem melancólica, nem apresentada. Durante um 
tempinho, ela nos deu um trabalho danado, mas Zana gostou dela. As duas rezavam juntas as orações que uma aprendeu em Biblos e a outra no orfanato das freiras, aqui em Manaus".

(HATOUM, 2006, p.48)

Assim, por meio do intercâmbio de experiências e do conhecimento do passado de Halim, Nael pode conhecer um pouco da origem de sua mãe. Também em outras passagens, o narrador confirma o caráter oral de sua narrativa, descrevendo o modo como constrói a tessitura do passado, que lhe é exposta na forma de estilhaços:

Desta vez Halim parecia baqueado. Não bebeu, não queria falar. Contava esse e aquele caso, dos gêmeos, de sua vida, de Zana, e eu juntava os cacos dispersos, tentando recompor a tela do passado.

"Certas coisas a gente não deve contar a ninguém", disse ele, mirando nos meus olhos.

Relutou, insistiu no silêncio. Mas para quem ia desabafar? Eu era o seu confidente.

(HATOUM, 2006, p.101 - grifo nosso).

Dois aspectos pragmáticos, característicos das narrativas orais, estão presentes na passagem: o desabafo e o conselho. Quando Halim diz que "certas coisas a gente não deve contar a ninguém", a narrativa parece sugerir aos leitores que a obediência a esse conselho é uma das estratégias discursivas do narrador. Assim cabe ao leitor indagar: Quanto Nael e os outros narradores ocultam da "tela do passado"? Lembrando que a incompletude é marca de todo e qualquer discurso, o leitor, no processo de leitura, como o próprio Nael, no ato de escrita, junta os cacos dispersos, tentando recompor essa tela do passado, que, contudo, deixa visíveis as fendas que constituem seu tecido.

Consequentemente, o reconhecimento da incompletude da narrativa torna-se peça fundamental para sua análise e para a reconstrução de seu sentido, uma vez que a verdade absoluta é inalcançável, particularmente devido ao distanciamento do narrador quanto aos fatos e à sua parcial ignorância em relação a eles. Privado dos traços próprios do narrador onisciente ou do narrador protagonista, Nael é um narrador imerso em dúvidas e, para ele, a verdade nada mais é do que uma possibilidade, o que é exemplificado na seguinte passagem: 
“Talvez por esquecimento, ele [Halim] omitiu algumas cenas esquisitas, mas a memória inventa, mesmo quando quer ser fiel ao passado. [...] Omissões, lacunas, esquecimento. $\mathrm{O}$ desejo de esquecer. Mas eu me lembro, sempre tive sede de lembranças, de um passado desconhecido, jogado sei lá em que praia do rio". (HATOUM, 2006, p.67)

O objetivo do narrar em Dois Irmãos configura-se, dessa forma, em uma dúvida insolúvel para o leitor: Quem é o pai de Nael? Yaqub ou Omar? Ou talvez Halim? A resposta não é dada por nenhuma personagem e, assim, o leitor compartilha do dilema do narrador, cuja narrativa expressa sinais do pós-moderno: a reconstituição da história a partir de uma perspectiva marginal, a incompletude do narrado, a presença de inúmeras vozes discursivas, a pluralidade de pontos de vista.

Todavia, embora viva à margem da família e da própria instituição educacional, o que significa estar à margem da sociedade, Nael alcança sua autoafirmação por meio do estudo e da escrita. A escola que frequenta é chamada de "Galinheiro de Vândalos", onde aqueles que são reprovados e indesejados em outras instituições acabam por aportar. Porém, mesmo sendo filho bastardo da família libanesa e "sentenciado" a serviçal da casa, posição similar à de sua mãe, Nael subverte sua condição social:

"Eu ia conseguir isso: o diploma do Galinheiro dos Vândalos, minha alforria. Sem que eu soubesse, Halim arrumava no meu quarto os manuais que o caçula desprezava e os muitos livros que Yaqub deixou ao viajar para São Paulo, em janeiro de 1950". (HATOUM, 2006, p.30 - grifo nosso)

A palavra alforria, de origem árabe, ganha, aqui, novas significações, agregando à ideia da liberdade individual, da independência financeira e intelectual - alcançada por meio da educação -, a do rompimento com a tradição "libanesa", a que Nael se vira aprisionado desde o nascimento. Ou seja, ao tornar-se independente, ele não precisa assumir uma tradição que lhe pertence geneticamente, mas que lhe foi negada nos espaços de interação social, para se circunscrever aos manuais desprezados por Omar, aos livros deixados às traças por Yaqub, às memórias seletivas de Halim e Zana.

Todo texto é incompleto, por isso é necessário um leitor competente para relacionar os sentidos do texto com os contextos, tanto com o de Dois Irmãos como com o do próprio leitor. O papel do leitor em Dois Irmãos é 
justamente recolher "os cacos" narrativos e compor uma tela discursiva. Umberto Eco lembra que o leitor "[...] é sempre postulado como o operador capaz de abrir, por assim dizer, o dicionário para toda palavra que encontre e de recorrer a uma série de regras sintáticas preexistentes para reconhecer a função recíproca dos termos no contexto da frase" (ECO, 2012, p.35). Para trabalhar com a narrativa em questão, o leitor precisa ter consciência do aspecto de incompletude que o texto apresenta e abstrair sentidos dos silêncios e não ditos da narrativa.

"Não-dito" significa não manifestado em superfície, a nível
de expressão: mas é justamente este não-dito que tem de ser
atualizado a nível de atualização de conteúdo. E para este
propósito um texto, de uma forma ainda mais decisiva do que
qualquer outra mensagem, requer movimentos cooperativos,
conscientes e ativos da parte do leitor. (ECO, 2012, p.36).

O leitor, como Nael, recolhe cacos e fragmentos para tecer a tela da história, recompondo-a por meio da audição da voz de Nael e das vozes que a acompanham e da inscrição de imagens visuais que o olhar de Nael institui na narrativa. Assim, o narrador constrói a narrativa, sugerindo uma apreensão renovada dos acontecimentos, pois "sempre que alguém assume a posição do observador e olha para algo, esse algo muda, pois a posição interfere nisso que é observado e antes da observação não existia" (ISER, 1999, p.76). Portanto, a narrativa de Dois Irmãos recria essa condição duplamente: primeiro, na observação da realidade e na escrita pelo narrador Nael; segundo, nas operações do leitor, que, como o narrador, participa da construção da narrativa.

Wolfgang Iser discute o papel da literatura na auto-interpretação do humano e revela a importância da mediação entre fictício e imaginário na produção do texto literário e na construção da subjetividade $(1999$, p.66). Esse processo de auto-interpretação e mediação é operado por Nael e pelo leitor da obra, que participam de encenações para alcançar a realidade, ainda que essa seja limitada e, por vezes, impalpável (ISER, 1999, p.76).

A relação de Nael com a escrita - por meio da qual circunscreve uma identidade familiar e social de que fora privado pela negação da paternidade - ressalta, também, aspectos discutidos por Michel Foulcault. Para o teórico, escrever sobre si mesmo exerce, para o sujeito, uma função de complementaridade, visto que lhe permite escapar da solidão e revelar 
os movimentos interiores da alma. Além disso, a escrita de si instaura a presença de um confidente, já que, ao expor uma avaliação sobre o que fez ou pensou, o narrador expõe o respeito pelo outro e sua vergonha por ações não louváveis, situando-se como um duplo que, simultaneamente, registra e acolhe os eventos narrados. Escrever sobre si é, pois, mostrar-se, revelarse ao outro, e dessa função confessional o leitor participa, ao se identificar com o receptor textual (FOUCAULT, p.145, 1997).

A mediação entre fictício e imaginário é condição para que o homem não permaneça estático e perceba a realidade e sua vida interior com novos olhos, podendo, então, conhecer-se mais profundamente. Nael concilia ficção e imaginação para compreender a realidade e, embora nunca descubra quem é seu pai, a escrita, ou a literatura, permite que ele conheça seu papel no mundo e encontre, por meio da narração, seu lugar na sociedade. Ao narrar, Nael se constitui como sujeito, que reflete sobre um contexto social e uma tessitura histórico-cultural, da qual também é fruto, comprovando que a literatura permite que o humano transcenda suas limitações.

\section{Considerações Finais}

Para a narração em Dois Irmãos, refluem diversas narrativas, formando um mosaico espaço-temporal em que significados podem ser comunicados, silenciados ou, até mesmo, apagados. Os sentidos construtores da narrativa são caracterizados pelo ouvir, pela presença do olhar, pela exposição da experiência do eu, mas também pela imprecisão. Isso ocorre porque Nael, o narrador, é uma personagem que, estando à margem da ação, assume o papel de observador, um observador dos outros, da casa, da vizinhança, da cidade, e, por fim, dele mesmo. Mas Nael é também um narrador que traduz o crucial dilema de não conhecer o nome do pai e de ignorar suas origens, dilema que ele tenta superar por meio da escrita, cujos traços reúnem a técnica de narrar, própria de um tempo passado, à dubiedade do dizer da pós-modernidade.

A transposição da oralidade, instituída por vozes múltiplas, a observação e a análise da experiência pessoal são recursos técnicos que compõem a subjetividade do narrador e a narrativa em Dois Irmãos. É por meio dessa estrutura, marcada pela linguagem coloquial dos contadores de histórias, mas também cheia de silêncios, ponderações, censuras e condicionamentos sociais, que o leitor recebe a narrativa e concebe sua compreensão, construindo uma rede de significados. Cabe ao leitor entrelaçar as diferentes 
histórias, preencher as lacunas do narrador, restando-lhe, assim como a Nael, a sensação de incompletude e o desejo de retornar ao já dito.

Nas palavras de Benjamin, a "experiência que passa de pessoa a pessoa é a fonte a que recorreram todos os narradores. E, entre as narrativas escritas, as melhores são as que menos se distinguem das histórias orais contadas pelos inúmeros narradores anônimos" (BENJAMIN, 1994, p.198). Já Santiago, retomando o posicionamento de Benjamin, afirma que a narrativa pós-moderna evidencia não só a pobreza da experiência, mas também da palavra escrita, enquanto processo de comunicação. Isso levaria escritores contemporâneos a conceberem narradores cujo saber é decorrente do olhar lançado sobre experiências de um outro, e não mais do mergulho em vivências próprias. A partir dessa perspectiva, a narrativa deixa de expor os acontecimentos narrados como "verdades", mas instala a dúvida e a imprecisão, as quais lhe conferem, em um tempo marcado pela falência das certezas, a verossimilhança necessária à ativa participação do leitor.

Em Dois Irmãos, conjugam-se as duas técnicas de narrar: os relatos forjados no âmbito da vida e marcados pela oralidade chegam a Nael como histórias cheias de subentendidos que ele registra, combinandoas com sua própria experiência. Todavia, a pergunta que Nael formula não encontra respostas, e mesmo a leitura mais minuciosa e precisa não é capaz de solucionar o dilema que ele vivencia e que inscreve no texto. Questionamentos e dúvidas são, porém, um dos méritos da narrativa, cuja abertura garante a permanência na mente de seu receptor e a ele confere o desejo de voltar ao enigma da narrativa de Milton Hatoum.

\section{Referências}

BENJAMIN, Walter.

(1994). 0 narrador: considerações sobre a obra de Nikolai Leskov. Magia e técnica, arte e política: ensaios sobre literatura e história da cultura. São Paulo, Brasiliense. p. 197-221.

ECO, Umberto.

(2012) 0 leitor-modelo. In: Humberto Eco; Lector in fabula. São Paulo, Perspectiva. p.3549.

FOUCAULT, Michel

(1997) 0 que é um autor?. Lisboa, Ed. Vega Colecção Passagens.
HATOUM, Milton.

(2006). Dois Irmãos. São Paulo, Companhia das Letras.

HUTCHEON, Linda.

(1991). Poética do pós-modernismo: história, teoria, ficção. Rio de Janeiro, Imago.

ISER, Wolfgang.

(1999). 0 fictício e o imaginário. In: Cezar de Castro Rocha (Org); Teoria da ficção: indagações à obra de Wolfgang Iser. Rio de Janeiro, Ed. UERJ. p.65-77. 
RICOEUR, Paul.

(1994). Tempo e narrativa, a tríplice mimese. In: Paul Ricoeur; Tempo e Narrativa. Tomo I. Campinas, Papirus. p.85-136.

SANTIAG0, Silviano.

(2002). 0 narrador pós-moderno. In: Silviano Santiago; Nas malhas das letras. Rio de Janeiro, Rocco. p. 44-61.
SARAIVA, Juracy Assmann.

(2009). 0 estatuto do narrador. In: Juracy Assmann Saraiva; 0 circuito de memórias. São Paulo, Edusp. p.25-40.

\section{Recebido em}

setembro de 2016

Aprovado em

maio de 2017 